DOI https://doi.org/10.46845/2541-8254-2021-3(30)-3-3

УДК 796

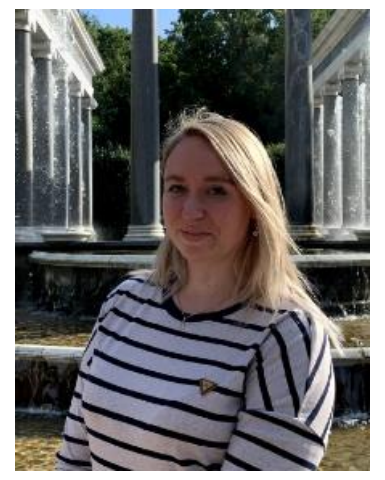

\title{
ИССЛЕДОВАНИЕ МОРФОФУНКЦИОНАЛЬНЫХ ХАРАКТЕРИСТИК СТУДЕНТОВ ТЕХНИЧЕСКОГО ВУЗА, ОТНЕСЁННЫХ К ПЕРВОЙ И ТРЕТЬЕЙ ГРУППАМ ЗДОРОВЬЯ
}

\author{
Е. Э. Киселёва, студентка 3-го курса, \\ e-mail: ms.pepper2000@mail.ru \\ ФГБОУ ВО «Калининградский государственный \\ технический университет»
}
М. А. Пыленок, преподаватель физической культуры, e-mail:marina.pylenok@klgtu.ru
ФГБОУ ВО «Калининградский государственный технический университет»

В данной статье рассматривается понятие физической активности, производимое скелетными мышцами, которое требует расхода энергии. Даются определения ИМТ (индекс массы тела), мышечной массы, висцерального жира. Написанная работа знакомит с результатами исследования в области физической активности студентов. Делается вывод о её влияние на организм разных групп респондентов.

Ключевые слова: физическая активность, мышечная масса, кистевая динамометрия, окружность грудной клетки

\section{ВВЕДЕНИЕ}

Под определением физическая активность понимается движение тела скелетными мышцами с затратой энергии во время различных занятий. Сам же термин не следует путать с понятием упражнение, которое направлено на улучшение или поддержание компонентов физического состояния и входит в состав категории физической активности [1].

\section{ОБЬЕКТЫ ИССЛЕДОВАНИЯ}

Студенты вуза основной и специальной медицинской групп.

\section{ЦЕЛИ И ЗАДАЧИ}

Цель: изучить морфофункциональные характеристики студентов с различными уровнями физической активности, провести исследование, которое покажет разницу между респондентами основной группы здоровья и специальной медицинской группы.

Задачи:

1. Собрать данные с помощью диагностического анализатора жировой массы Tanita BC-545N, динамометра, сантиметровой ленты.

2. Обработать информацию.

3. Сравнить полученные результаты за весь период исследования.

\section{МЕТОДЫ ИССЛЕДОВАНИЙ}

Собранные данные получены путём эмпирических методов анализа.

\section{РЕЗУЛЬТАТЫ ИССЛЕДОВАНИЯ}

Физическую активность делят на три основных направления:

1. Упражнения на развитие гибкости.

2. Упражнения на укрепление сердечно-сосудистой системы (кардио или аэробные). 
3. Упражнения на увеличение силы и поддержание мышц в тонусе (анаэробные).

Вышеуказанные виды физической активности сопровождаются запуском обменных процессов, которые нуждаются в поступлении дополнительного количества кислорода и питательных веществ. Уже при лёгкой и тем более при интенсивной физической активности происходит повышение ЧСС, а также увеличение частоты дыхания с повышением газообменных процессов. Метаболизм характеризуется не только поступлением, но и выведением продуктов, образующихся в процессе жизнедеятельности клеток. Поступившие вещества вначале всасываются в кровь, а затем выводятся вместе с мочой, потом и лёгкими при дыхании $[3,4]$.

Поэтому при увеличении нагрузки у человека появляются учащенное сердцебиение и пульс, одышка, усиливается потоотделение. Такие проявления в организме помогают защитить его от негативных последствий в период тренировок. Но регулярные занятия помогают не только укреплению и поддержанию здоровья, но и уменьшают риск развития важнейших социально значимых заболеваний. Физическая активность оказывает положительное влияние на здоровье, и повышает уровень жизни [5].

Преимущества регулярной физической активности помогают снизить риски развития многих заболеваний, таких как инфаркт, рак, гипертония, а также нормализуют вес, сон и улучшают координацию и самочувствие [2].

В ходе работы я провела исследование, в котором приняли участие студенты, относящиеся к основной группе здоровья и спецмедгруппы.

Общее количество респондентов, которые проявили заинтересованность, составляет 52 человека. Из них 14 юношей, остальные девушки.

Замеры проводились с помощью диагностического анализатора жировой массы Tanita BC-545N (рис. 1), который отображал следующие показатели, представленные на профилограмме. На диаграммах (рис. 2-3) представлены морфофункциональные показатели студентов основной и спецмедгруппы 1-й замер за октябрь, 2019 г., 2-й замер за февраль, 2020 г., 3-й замер за март 2021 г.
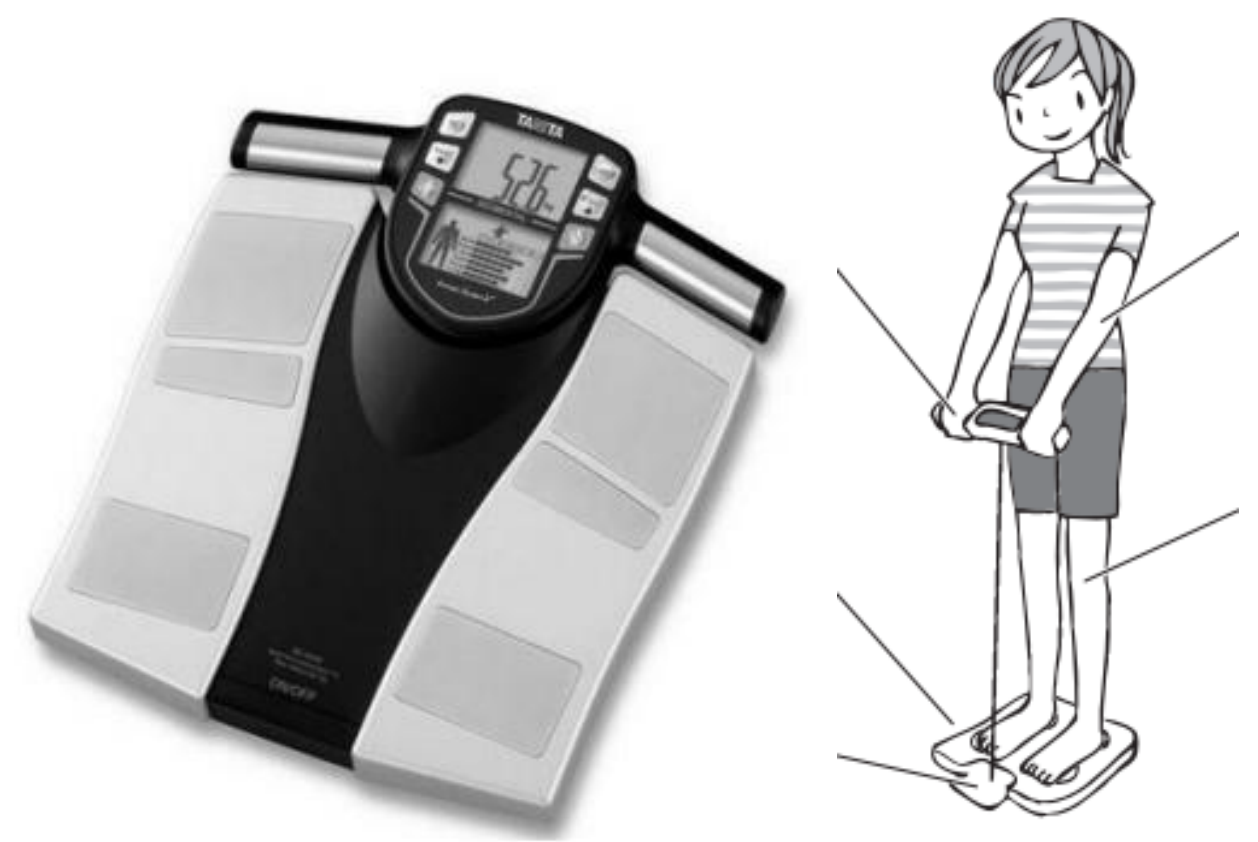

Рисунок 1 - Диагностический анализатор жировой массы Tanita BC-545N 


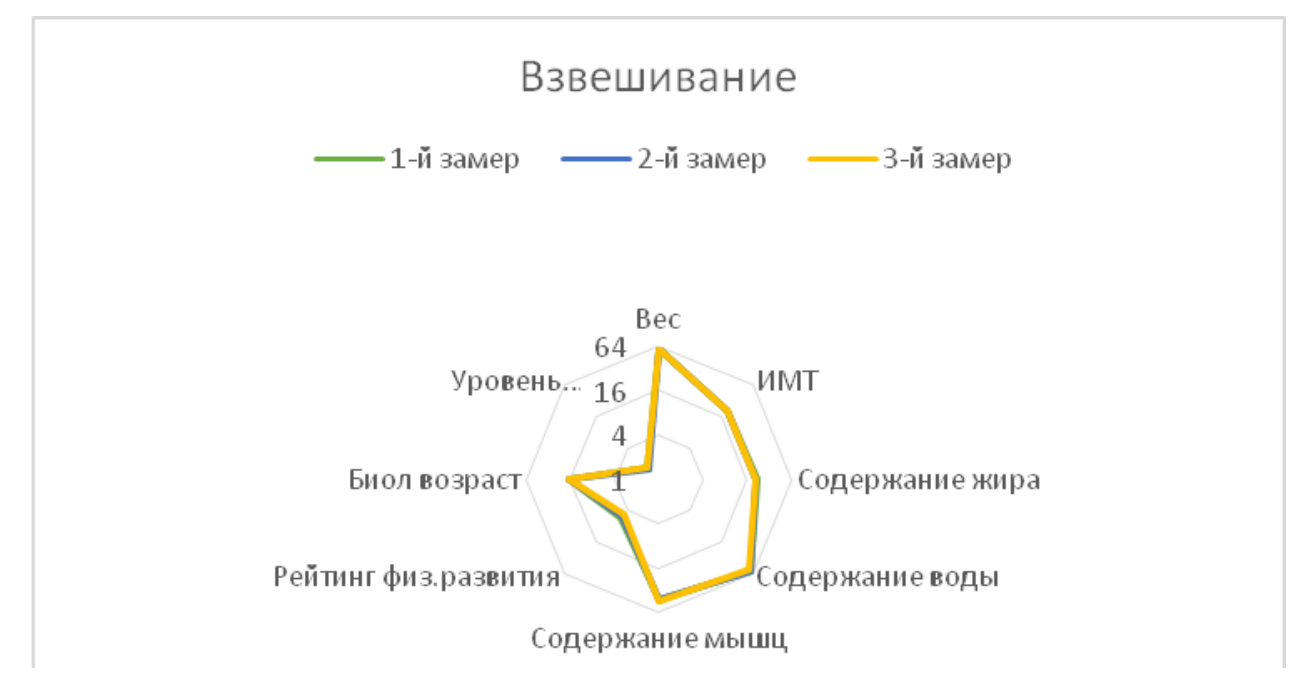

Рисунок 2 - Морфофункциональные характеристики основной группы студентов КГТУ за период 2019-2021 гг.

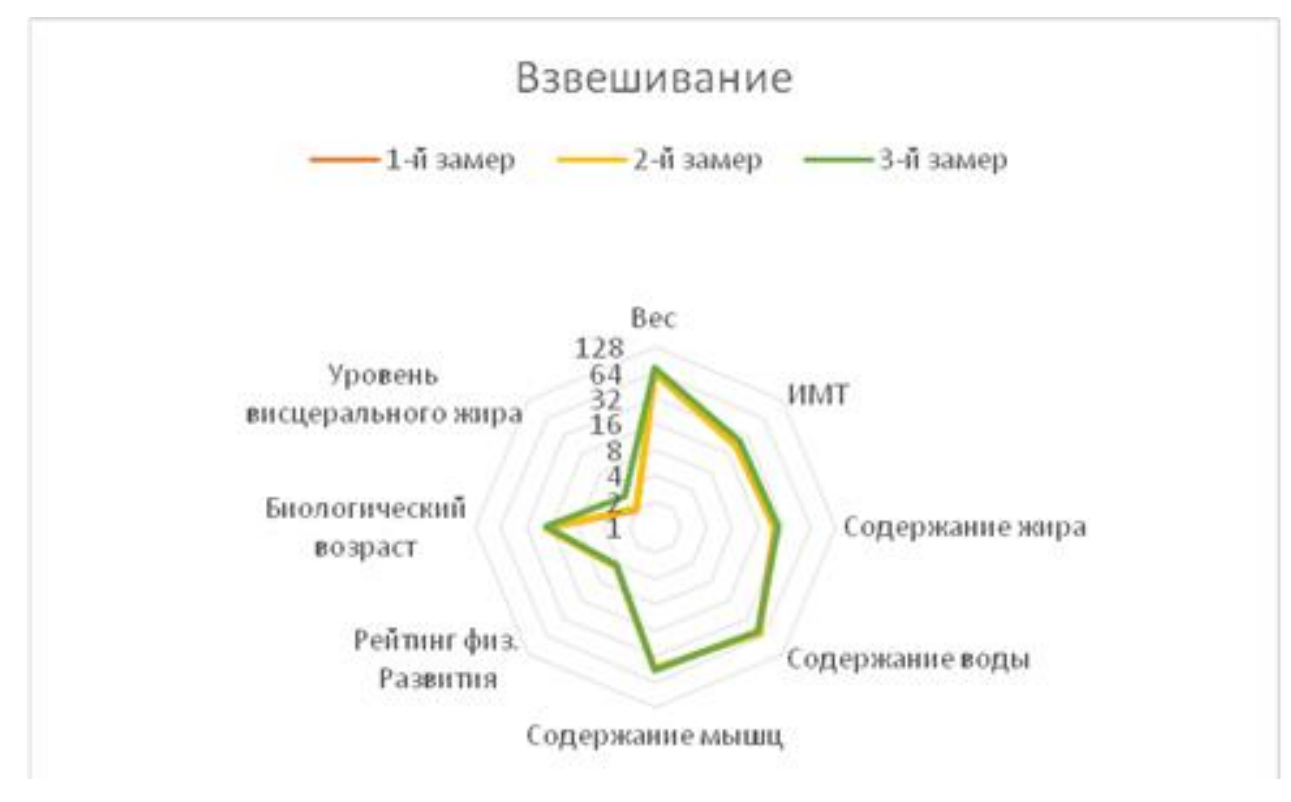

Рисунок 3 - Морфофункциональные характеристики спецмедгруппы студентов КГТУ за период 2019-2021 гг.

Индекс массы тела (ИМТ) - величина, которая показывает, как соотносятся рост и масса человека, что позволяет косвенно оценить, к какой из категорий он относится. Средняя масса студентов оказалось нормальной.

По содержанию жира можно определить процент жировой ткани в организме человека. Так как специальная медицинская группа менее активна, то процент содержания жира у них больше, чем у основной группы [9].

Процент содержания воды в организме - общее количество жидкости в человеческом организме в процентах от его общего веса. Нормальный уровень воды составляет 50-60 \%, что видно по профилограммам (рис. 2-3) [6].

Мышечная масса - параметр, который демонстрирует нам вес мышечной массы в организме, включая скелетные и гладкие мышцы, а также воду, содержащуюся в них. Её можно набрать, прибегнув К помощи регулярных тренировок и правильного сбалансированного питания, при этом содержание жира останется почти неизменно [8]. 
Под понятием костная масса понимают вес скелетных костей в организме, а именно минеральную часть, которая на протяжении жизни, если Вы остаетесь в одной и той же весовой категории, не изменяется.

Если метаболический, т. е. биологический возраст, старше физического, то следует предпринять меры по его снижению. Повышение нагрузки позволит нарастить мышечную массу, в результате чего произойдёт уменьшение биологического возраста.

Что же такое уровень висцерального жира. Висцеральный жир - это тоже жировое накопление нашего организма, но скапливается он не вокруг талии и бедер, а вокруг органов брюшной полости. Он опаснее, чем обычный подкожный жир, да и бороться с ним также намного сложнее [9]. $4-5)$.

Следующие данные получены с помощью динамометра и сантиметровой ленты (рис.

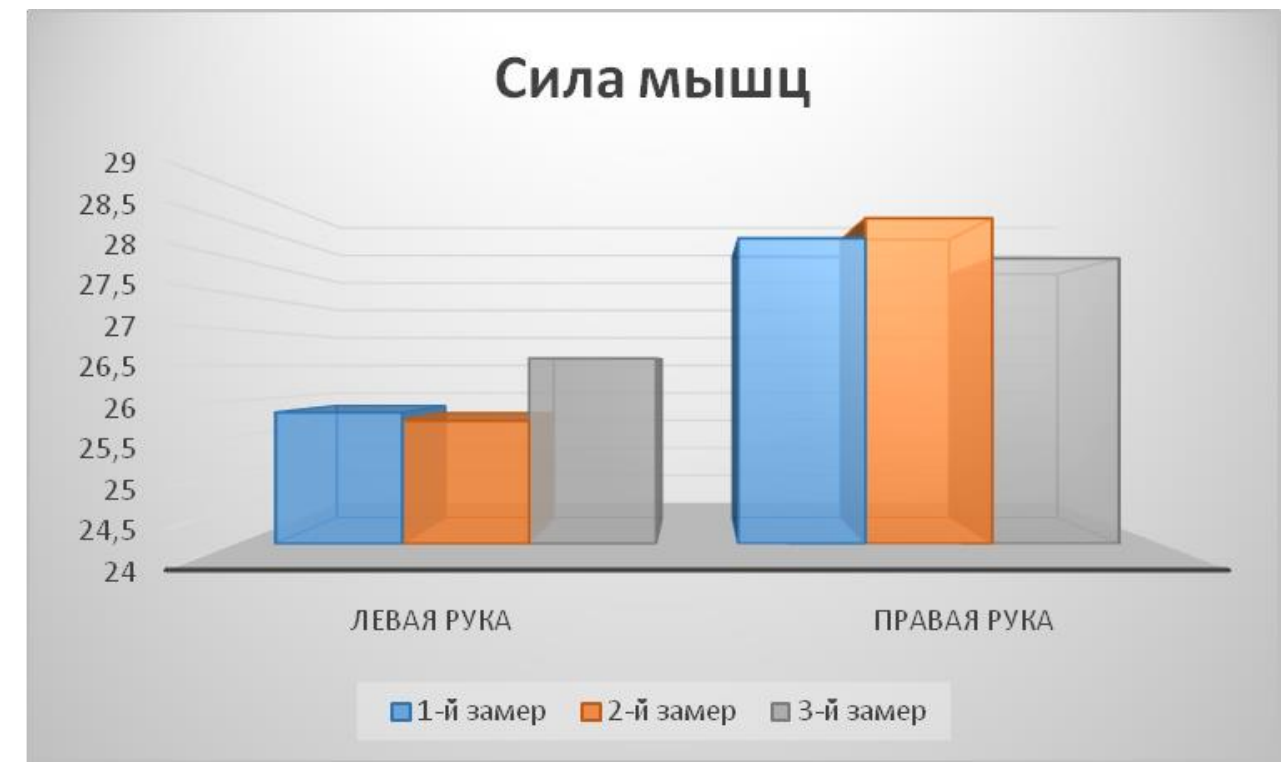

Рисунок 4 - Морфофункциональные показатели силы основной группы студентов КГТУ

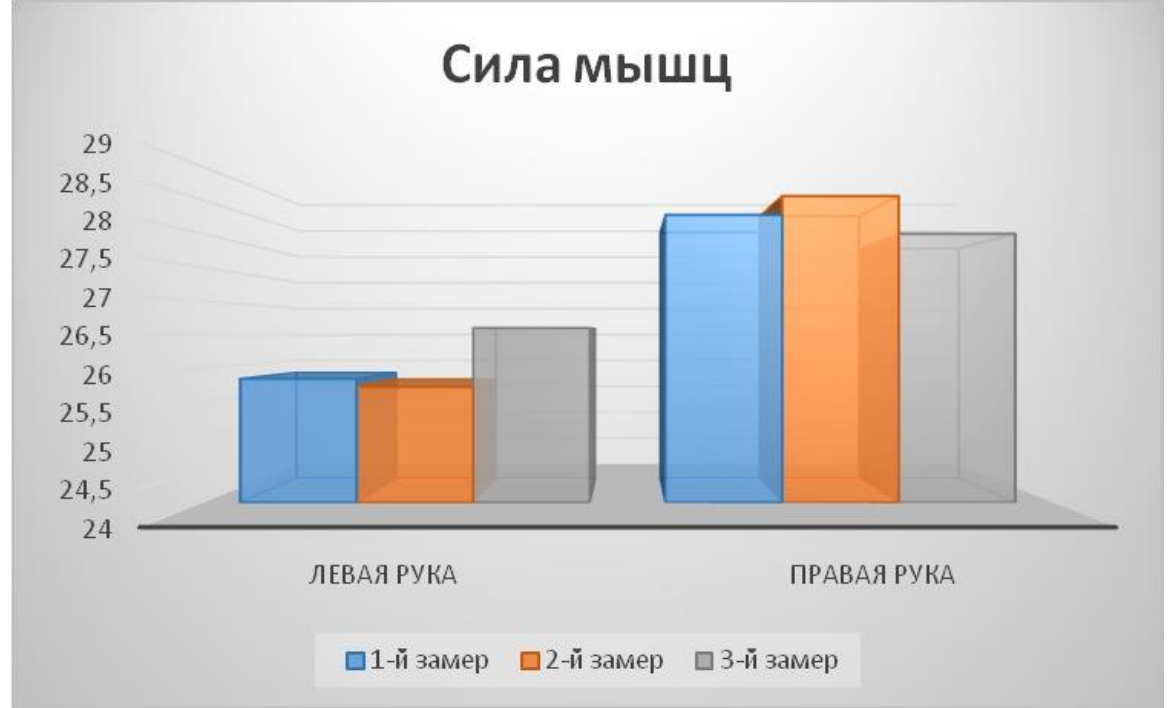

Рисунок 5 - Морфофункциональные показатели силы спецмедгруппы студентов КГТУ 


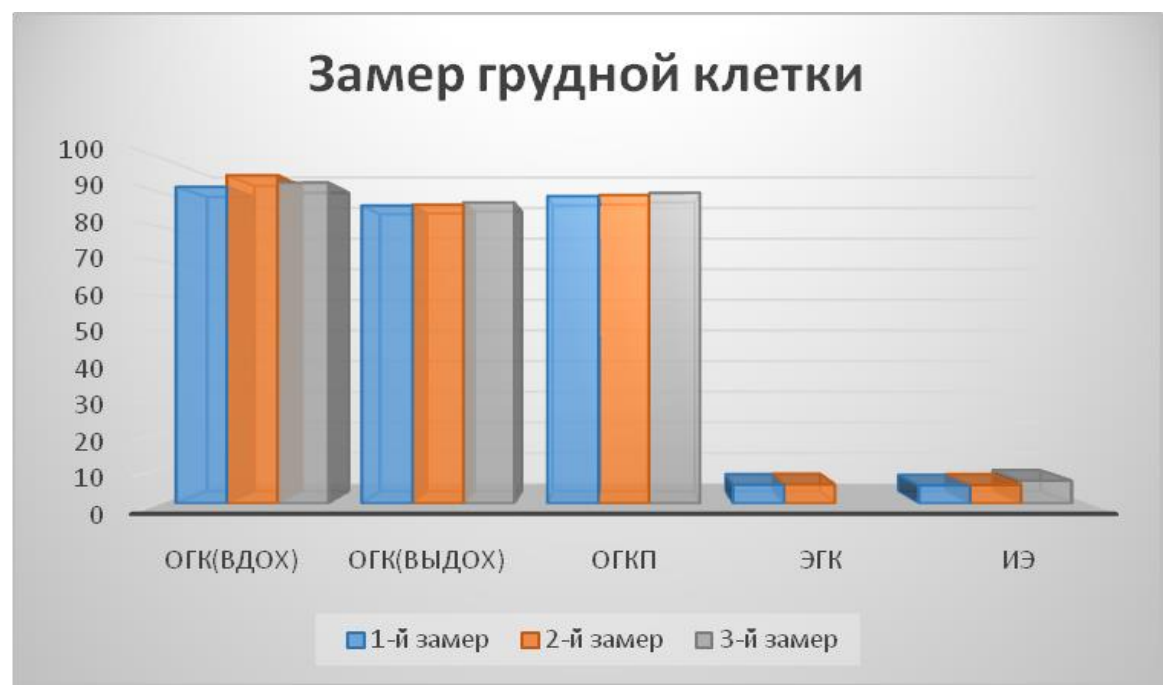

Рисунок 6 - Морфофункциональные характеристики окружности грудной клетки основной группы студентов КГТУ

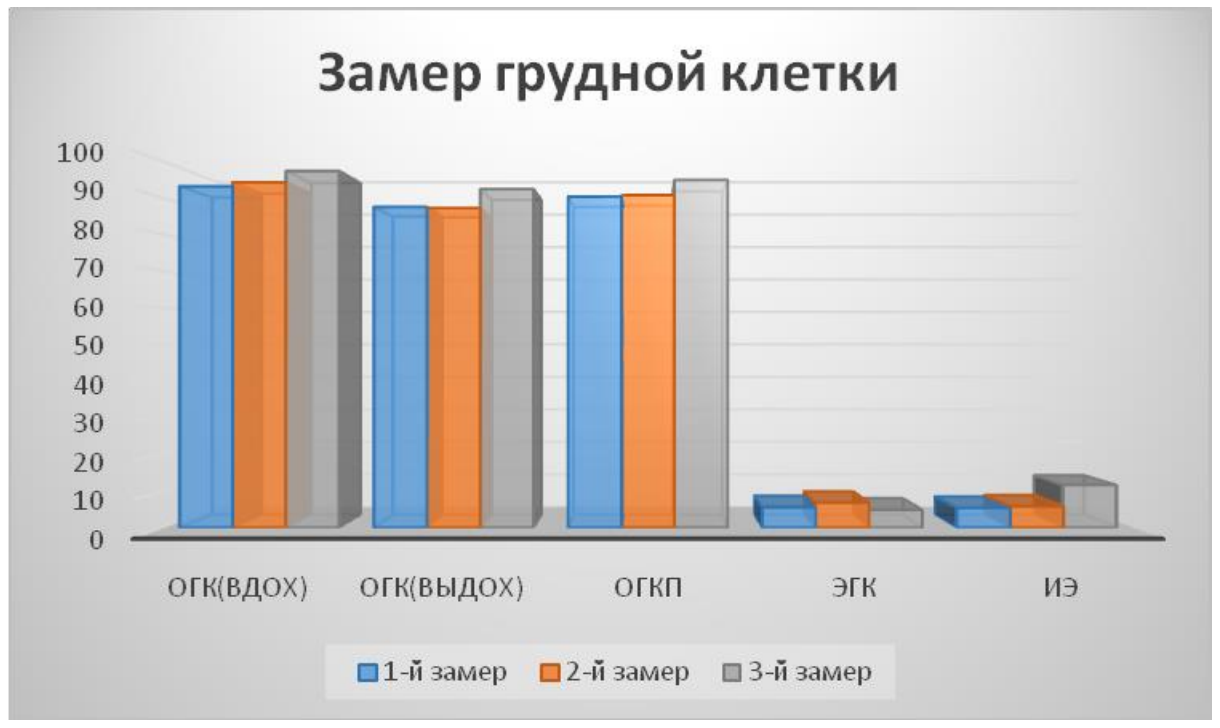

Рисунок 7 - Морфофункциональные характеристики окружности грудной клетки студентов третьей группы здоровья КГТУ

Кистевая динамометрия - оценка силы кистей рук. Проводится с помощью динамометра. Сила мышц правой и левой кисти определялась в положении стоя кистевым динамометром при отведении в сторону поднятой до уровня плеч руки, без рывков. При наблюдении разницы следует воспользоваться комплексом упражнений, отвечающим за рост мышц.

Нами была определена окружность грудной клетки (ОГК), данные предоставлены на диаграмме (рис. 6-7). По итогам измерений рассчитывалась окружность грудной клетки в паузе по формуле:

$$
\text { ОГКп }=0,5 *(\text { ОГК на вдохе }+ \text { ОГК на выдохе }) .
$$

Далее рассчитывался параметр «экскурсия грудной клетки» по формуле:

$$
\text { ЭГК }=\text { ОГК вдох }- \text { ОГК выдох, }
$$

где ОГК клетки на выдохе.

Также мы рассчитывали значение индекса развития грудной клетки Эрисмана:

$$
\text { ИЭ = ОГКп - Н/2, }
$$


где ОГКп - окружность грудной клетки в паузе (см); Н - рост тела (см).

\title{
ЗАКЛЮЧЕНИЕ
}

В работе рассмотрены морфофункциональные характеристики студентов, относящихся к первой и третьей группам здоровья с различными уровнями физической активности, приведены данные исследования, которое показывает разницу между респондентами основной группы и спецмедгруппы. Сравнивая по некоторым параметрам изменения, можно сделать вывод, что их почти нет, так как специальная медицинская группа следит за своим здоровьем, посещая, например, бассейн, ледовую арену, а также различные спортивные мероприятия для поддержания своего физического развития и функциональных возможностей организма [7].

\section{СПИСОК ИСПОЛЬЗОВАННОЙ ЛИТЕРАТУРЫ}

1. Физическая активность / Всемирная организация здравоохранения [Электронный ресурс]. - URL: https://www.who.int/ru/news-room/fact-sheets/detail/physicalactivity. (Дата обращения: 29.05.2021).

2. Физическая активность и здоровье / ФБУЗ «Центр гигиенического образования населения» Роспотребнадзора [Электронный ресурс]. - URL: http://cgon.rospotrebnadzor.ru/content/62/3311/. (Дата обращения: 29.05.2021).

3. Физическая активность / Greenportal [Электронный pecypc]. - URL: https://greenportal.pro/physical_activity/fizicheskaya-aktivnost/. (Дата обращения: 29.05.2021).

4. Физическая активность / Мир здоровья [Электронный ресурс]. - URL: https://mir-zdorovja.com/fizicheskaya-aktivnost/. (Дата обращения: 29.05.2021).

5. Физическая активность / Минздрав [Электронный ресурс]. - URL: http://minzdrav.gov.by/dlya-belorusskikh-grazhdan/profilaktika-zabolevaniy/dvigatelnayaaktivnost/fizicheskaya-aktivnost.php. (Дата обращения: 29.05.2021).

6. Рекомендации по питанию спортсменов. - Москва: Физкультура и спорт, 2004.

7. Скурихин, И. М. Как правильно питаться / И. М. Скурихин. - Москва, 2008.

8. Физическая активность / Управление Федеральной службы по надзору в сфере защиты прав потребителей и благополучия человека [Электронный ресурс]. - URL: http://04.rospotrebnadzor.ru/index.php/san-nadzor/2015-10-01-05-48-10/10621-12042019.html. (Дата обращения: 29.05.2021).

9. Состав тела человека в процентах: подробное описание нормативов / [Электронный ресурс]. - URL: https://sledizavesom.ru/snizhenye-vesa/sostav-tela-chelovekav-procentakh.html. (Дата обращения: 29.05.2021).

\section{PHYSICAL ACTIVITY OF KSTU STUDENTS}

\author{
E. E. Kiseleva, 3rd year student, \\ e-mail: ms.pepper2000@mail.ru \\ Kaliningrad State Technical University
M. A. Pylenok teacher of physical culture, e-mail: marina.pylenok@klgtu.ru
Kaliningrad State Technical University

This article discusses the concept of physical activity produced by skeletal muscles, which requires energy consumption. Definitions of BMI (body mass index), muscle mass, visceral fat are given. The written work introduces the results of research in the field of physical activity of students. The conclusion is made about its effect on the body of different groups of respondents. 
Key words: physical activity, types, muscle mass, wrist dynamometry, chest circumference 